\title{
Teaching medical students and residents how to inject local anesthesia almost painlessly
}

\author{
Hana Farhangkhoee BMSc MSc MD ${ }^{1}$, Jan Lalonde RN², Donald H Lalonde BSc MSc MD FRCSC ${ }^{2}$
}

\begin{abstract}
H Farhangkhoee, J Lalonde, DH Lalonde. Teaching medical students and residents how to inject local anesthesia almost painlessly. Can J Plast Surg 2012;20(3):169-172.

The objective of the present study was to determine whether it is possible to consistently and reliably teach medical students and resident learners how to administer local anesthetics in an almost painless manner. Using the published technique, 25 consecutive medical students and residents were taught how to inject local anesthetics for carpal tunnel release by watching the senior author perform the technique once. The learner then independently administered the anesthesia to the next patient who then scored the learner's ability to inject the local anesthetic from a pain perspective. The teaching technique is demonstrated in an accompanying online video. The learners were consistently capable of administering local anesthetics with minimal pain. During the injection process, the patients only felt pain once ('hole-in-one') $76 \%$ of the time. This pain was attributed to the first 27 -gauge needle poke. The other $24 \%$ of the time, patients felt pain twice (eagle) during the 5 min injection process. All 25 patients rated the entire pain experience to be less than 2/10. Eighty-four per cent of the patients indicated that the experience was better than local anesthetic given at the dentist's office. Medical students and residents can quickly and reliably learn how to administer local anesthesia for carpal tunnel release with minimal pain to the patient.
\end{abstract}

Key Words: Carpal tunnel release; Local anesthesia; Medical education; Wideawake surgery

Some doctors and dentists are capable of injecting local anesthesia $\checkmark$ in a less painful manner than others. Is the art of administering local anesthetic in an almost painless manner a talent that people are fortunate to have, or is this a skill that can easily and reliably be taught to medical students and residents?

We have developed a scoring system by which the patients can actually measure and grade the amount of pain we generate as we inject local anesthesia. It is difficult to measure the intensity of pain, but we can easily measure the number of times a patient feels pain during the injection process. The scoring system used in the present study was as follows: if the patient felt pain only during the first poke of the needle used to inject the local anesthesia, then the patient reports he or she only felt pain once ('hole-in-one'). Each time that the patient felt pain again during the injection(s), they recorded this as another pain event. The patient may have felt pain twice (eagle), three times (birdie), four times or more (bogie). The golf analogy is helpful because it helps the surgeon, resident or medical student get a record of his or her ability. It also creates an environment that facilitates improvements in personal score or ability. The patients were asked to score each local anesthetic injection so there was constant feedback and improvement in the injector's ability to induce less pain during local anesthetic injection.

We have previously published a method of local anesthetic injection that is minimally painful for patients undergoing carpal tunnel release (CTR) (1) as well as for other operations such as cosmetic blepharoplasty (2).

\author{
Enseigner aux étudiants en médecine et aux \\ résidents à injecter un anesthésique local \\ pratiquement sans douleur
}

La présente étude visait à déterminer s'il est possible d'enseigner de manière constante et fiable aux étudiants en médecine et aux résidents à administrer un anesthésique local de manière pratiquement indolore. Au moyen de la technique publiée, 25 apprenants consécutifs, des étudiants en médecine et des résidents, se sont fait enseigner à injecter un anesthésique local en vue de libérer le nerf médian au niveau du canal carpien en regardant l'auteur chevronné effectuer la technique une fois. L'apprenant administrait ensuite seul l'anesthésique au patient suivant, qui évaluait la capacité de l'apprenant à injecter l'anesthésique local selon la douleur ressentie. La technique d'enseignement est démontrée dans une cybervidéo d'accompagnement. De manière uniforme, les stagiaires étaient en mesure d'administrer l'anesthésique local en causant une douleur minimale. Pendant le processus d'injection, les patients ne ressentaient la douleur qu'une fois (trou d'un coup) dans $76 \%$ des cas. Cette douleur était attribuée à la première piqûre d'aiguille de calibre 27. Dans les $24 \%$ d'autres cas, les patients ressentaient de la douleur deux fois (aigle) pendant le processus d'injection de cinq minutes. Les 25 patients ont classé l'expérience globale de douleur à moins de 2/10. Quatre-vingt-quatre pour cent des patients ont indiqué que l'expérience était moins douloureuse qu'un anesthésique local administré au cabinet du dentiste. Les étudiants en médecine et les résidents peuvent apprendre rapidement et de manière fiable à administrer un anesthésique local en vue de libérer le nerf médian au niveau du canal carpien en causant une douleur minimale au patient.

The purpose of the present study was to evaluate whether the method of minimal pain injection of local anesthesia could be reliably and consistently taught to medical students and residents who rotate through our service.

\section{METHODS}

Ethics approval was obtained from the Research Ethics Board of the Saint John Regional Hospital (Saint John, New Brunswick) in accordance with the ICH Harmonized Tripartite Guidelines Ethics. The research protocol conformed to the ethical guidelines of the 1975 Declaration of Helsinki.

In the present prospective study, 25 consecutive CTR surgery patients who were willing to be injected by medical students or residents were recruited. They were required to be capable of understanding the concept of being injected by a learner, and had to be willing and capable of scoring the learner's performance. Before the study, written and verbal informed consent was obtained from the volunteer patients. Patients were excluded from the study if they refused to be injected by a learner. The demographic data of the participants were collected.

Between February 2009 and June 2011, 25 consecutive medical students $(n=9)$ and residents $(n=15)$ observed the senior author (DL) inject lidocaine and epinephrine into the distal wrist and palm of one patient who was about to undergo CTR. After watching the single injection by the surgeon, each learner then proceeded to inject the next volunteer patient without the supervision of the surgeon ("watch

${ }^{1}$ Division of Plastic and Reconstructive Surgery, McMaster University, Hamilton, Ontario; ${ }^{2}$ Division of Plastic and Reconstructive Surgery,

Dalhousie University, Saint John, New Brunswick

Correspondence: Dr Donald H Lalonde, Dalhousie University, Hilyard Place, 600 Main Street, Suite C204, Saint John, New Brunswick E2K 1J5.

Telephone 506-648-7950,fax 506-849-1340, e-mail drdonlalonde@nb.aibn.com 


\section{TABLE 1}

\section{Questionnaire and responses for the 'hole-in-one'}

\section{How many times did you feel the pain?}

$\begin{array}{lr}1 \text { (hole-in-one) } & 76 \\ 2 \text { (eagle) } & 24 \\ 3 \text { (birdie) } & 0 \\ 4 \text { (bogie) } & 0 \\ >4 \text { (double bogie) } & 0\end{array}$

2. How would you rate the pain of the whole experience? (scale of 0-10)

$\begin{array}{lr}0=\text { No pain at all } & 28 \\ 0.5 & 20 \\ 1 & 40 \\ 2 & 12 \\ 10=\text { Most pain imaginable } & 0\end{array}$

3. How would you compare the pain of the local anesthesia with the average dentist's local anesthesia?

Worse

Better

84

Same

8

I don't know

8

4. How would you compare the pain of the local anesthesia to the pain of an intravenous needle to be put to sleep for general anesthesia?

Worse

0

Better

68

Same

12

I don't know

20

5. Would you rather have been put to sleep or given sedation to have your carpal tunnel surgery?

Yes

0

No

100

Data presented as \%

one, do one'). The learner was scored on this first postdemonstration injection only. There were no 'practice injections'.

After the injection, the patient scored the trainee's minimal pain injecting ability by completing a questionnaire (Table 1) without the surgeon or the learner present. The patient was asked how many times he or she felt pain during the entire $5 \mathrm{~min}$ injection process (once, twice, three time, etc). If the patient only felt the pain of the first poke of the first injection, the patient registered this as a single episode of pain during the injection ('hole-in-one'). If the patient felt pain twice (eagle), they said they felt pain twice, etc. Although this measurement tool has not been validated, it was easily understood by all patients and learners in the study.

The patients were asked to compare the pain of their CTR operation with the pain of a dental procedure and the pain of an intravenous needle insertion for sedation or general anesthesia; if they would prefer sedation or general anesthesia if they had to undergo surgery again; and to rate the total pain experience from 0 to $10(0=$ no pain at all and $10=$ most pain they could imagine). An independent observer evaluated the results of the questionnaire.

\section{Method of injection}

A total of $20 \mathrm{~mL}$ of $1 \%$ lidocaine with 1:100,000 epinephrine $+2 \mathrm{~mL}$ of $8.4 \%$ bicarbonate was used to achieve anesthesia and hemostasis (Figures 1 to 4 ). The injections were performed slowly over a $5 \mathrm{~min}$ interval with a 27 -gauge needle. Ten millilitres of solution was slowly injected in the volar wrist under the skin and then under the forearm fascia between the median and ulnar nerves, and another $10 \mathrm{~mL}$ was injected subcutaneously into the palm. By slowly injecting a large volume, and by always making sure there is at least $5 \mathrm{~mm}$ of palpable local anesthesia ahead of the slowly advancing needle, the patients feel very little pain. It is important to make sure the tip of the needle never gets ahead of the advancing wheel of local anesthesia. When the needle is removed and reinserted into a new area, there should be at least $5 \mathrm{~mm}$ of blanched skin where the needle goes into the new site to be sure the patient does not experience a new pain episode at the new injection site. The goal is to get at least $5 \mathrm{~mm}$ to $10 \mathrm{~mm}$ of firm, white, tumescent subcutaneous tissue on either side of any incision or dissection area. The method of teaching this to the learners is clearly demonstrated in an online video (go to www.pulsus.com).

\section{RESULTS}

The mean $( \pm$ SD) age of the patients was $56 \pm 14$ years. Sixty-eight per cent of the patients were women and $32 \%$ were men. The learner's level of training was either medical student $(36 \%)$ or a resident (64\%).

The results demonstrated that all consecutive 25 learners were capable of administering local anesthetics with either only one or two episodes of pain felt by the patient during the injection process. Seventy-six per cent of the learners were able to have the patient only feel the pain of the first poke of the first injection ('hole-in-one'), while $24 \%$ had the patients feel pain twice during the injections (eagle). None of the learners caused more than two pain events. When comparing the female and male patient samples separately, $71 \%$ and $88 \%$ experienced a 'hole-in-one', respectively. Eight-eight per cent of all the patients rated the whole pain experience $\leq 1 / 10$. The remaining $12 \%$ reported a pain level of between 1 and 2 on the 0 to 10 pain scale.

Eighty-four of the volunteer patients stated that the pain of the injection induced by the learners was less than the pain experienced in an average dentist's office for local anesthetics. Eight per cent could not make the comparison because they had no dental experience. Sixty-eight per cent of the patients indicated that the experience was better than receiving a needle for general anesthetic. All 25 of the patients would prefer local anesthesia to general anesthesia or sedation for CTR.

\section{DISCUSSION}

Our data provide evidence that it is possible to consistently and reliably teach medical students and residents how to inject local anesthesia over a relatively large area in an almost pain-free manner. We were able to teach 25 consecutive learners how to inject CTR surgery patients in such a way that $76 \%$ of the patients only felt the pain of the first poke of the first injection, and no subsequent pain at all. The other $24 \%$ of the patients felt pain only two times during the entire $5 \mathrm{~min}$ of the injection. All of the patients rated the pain experience at $<2 / 10$ on the standard 0 to 10 pain scale. The learners only had to watch the technique once and were then able to inject the patients who suffered minimal pain. A clear demonstration of teaching this technique to a medical student can be viewed in the online training video (go to www.pulsus.com).

The three most important principles of inducing minimal pain during injection of local anesthesia are the following (2):

1. Use a smaller gauge needle (27-gauge for hand injection and 30 -gauge for face injection). This forces the injector to remember to proceed more slowly than is allowed with the standard 25 -gauge needle;

2. 'Blow slow before you go'. There should always be at least $5 \mathrm{~mm}$ of firm palpable local anesthesia in the skin ahead of the needle tip so the needle tip never penetrates an area that is not anesthetized except for the first poke of the first needle penetration. Inject slowly so the lidocaine has time to work ahead of the needle tip;

3. Use $1 \mathrm{~mL}$ of $8.4 \%$ bicarbonate with each $10 \mathrm{~mL}$ of lidocaine with $1: 100,000$ epinephrine (3). It is convenient that standard $10 \mathrm{~mL}$ syringes actually hold $11 \mathrm{~mL}$, and that $20 \mathrm{~mL}$ syringes actually hold $22 \mathrm{~mL}$.

Eighty-four per cent of our volunteer patients stated that the pain of the injection induced by the learners was less than the pain experienced in an average dentist's office for local anesthetics. Sixtyeight per cent of the volunteer patients reported that the pain they 


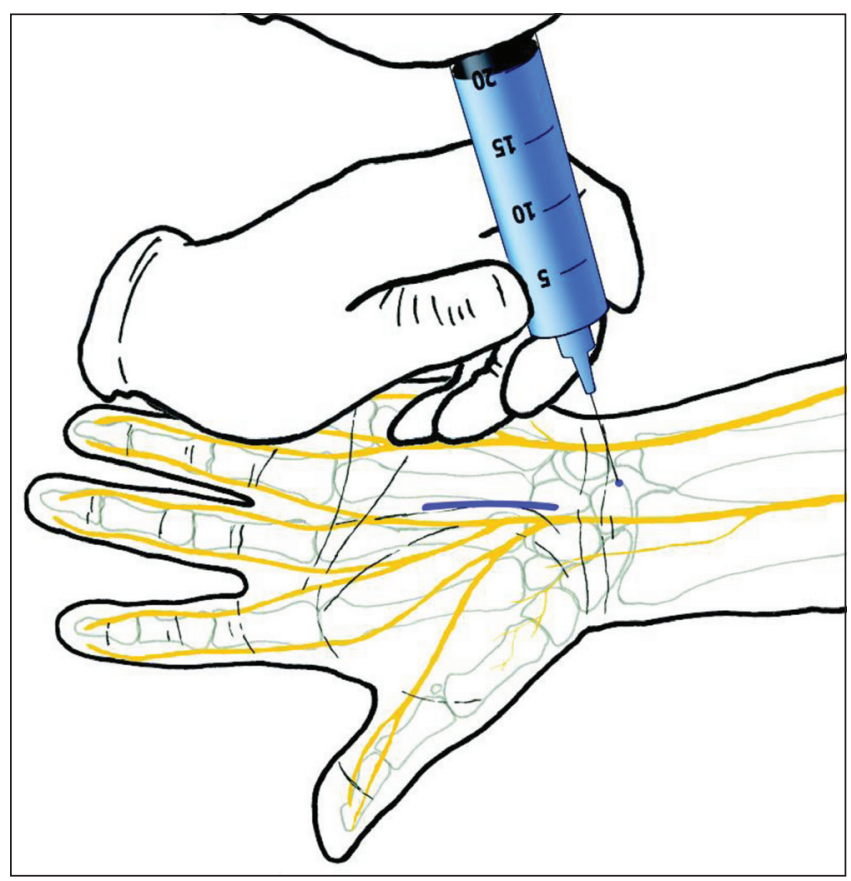

Figure 1) 'Hole-in-one' technique for injecting local anesthetics. Step 1:20 mL of 1\% lidocaine with 1:100,000 epinephrine (in blue for illustration purposes) will be used to provide hemostasis and avoid the need for a tourniquet, and to provide anesthesia, which lasts an average of $4 \mathrm{~h}$ to $5 \mathrm{~h}$. Reproduced with permission from reference 1

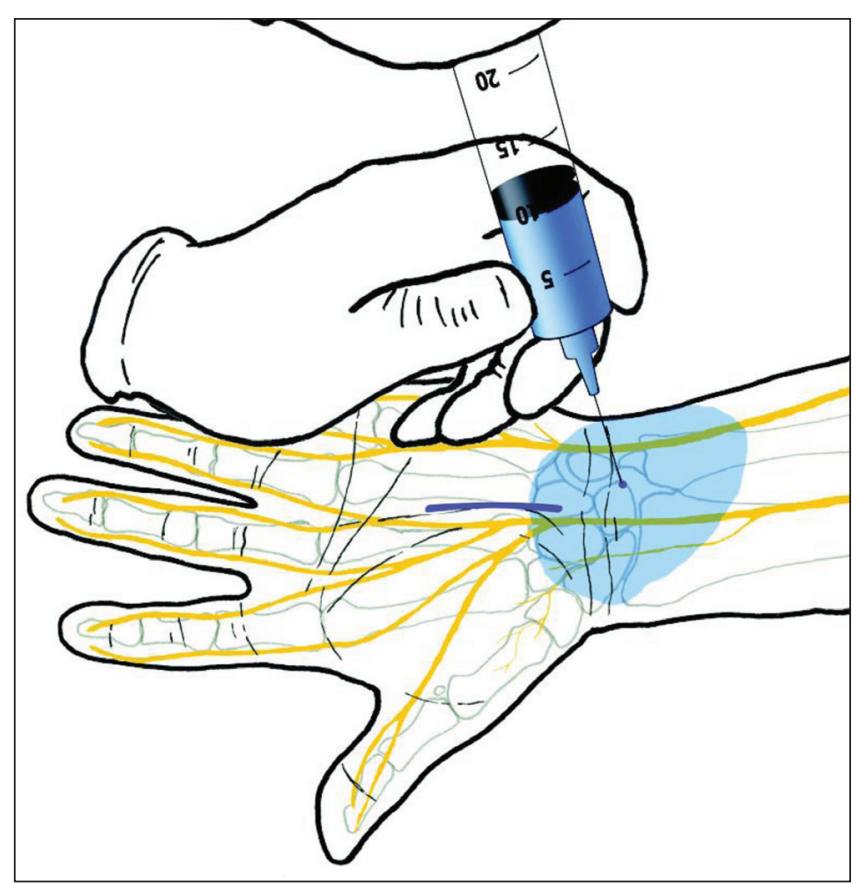

Figure 2) 'Hole-in-one' technique for injecting local anesthetics. Step 2: $10 \mathrm{~mL}$ is very slowly injected under the skin and under the forearm fascia to bathe the space of the median and ulnar nerves. The needle is moved very little, as shown in the video (www.pulsus.com). The tumescent effect of a slowly injected large volume and a nonmoving needle permits the patient to only feel the pain of the first poke of the 27-gauge needle into the skin (ie, 'hole-in-one'). Reproduced with permission from reference 1

experienced in the learner injections was less than the pain experienced with insertion of the usual 20-gauge intravenous needle used for providing medication for sedation or general anesthetics. Interestingly, $100 \%$ of patients stated that they would rather not be put to sleep

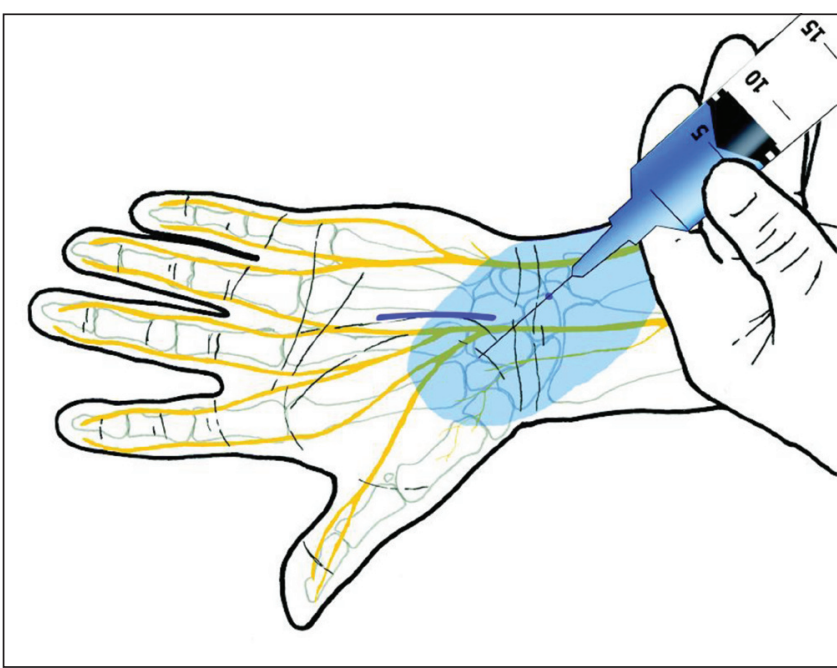

Figure 3) 'Hole-in-one' technique for injecting local anesthetics. Step 3: $2 \mathrm{~mL}$ to $3 \mathrm{~mL}$ are injected subcutaneously on the radial side of the proximal palm to be certain the palmar cutaneous branch is well bathed. This is also performed with very little needle movement and by allowing the tumescent spreading of the anesthetic solution to proceed in a pain-free manner. Reproduced with permission from reference 1

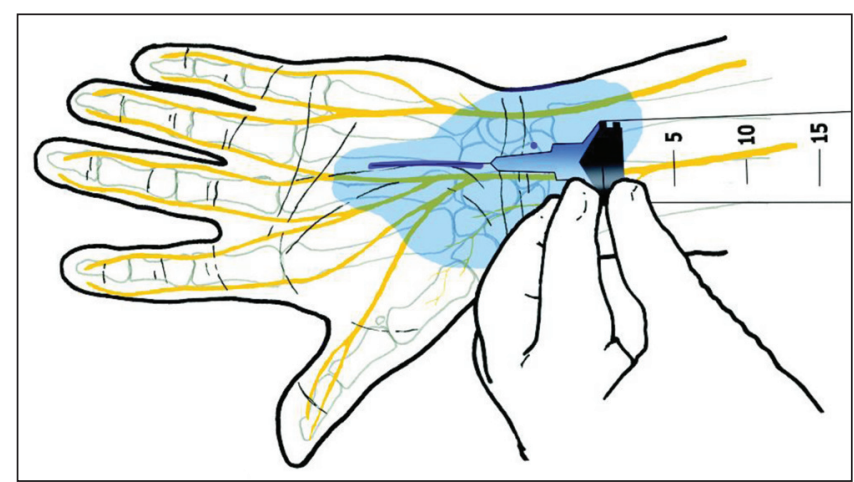

Figure 4) 'Hole-in-one' technique for injecting local anesthetics. Step 4: The final $7 \mathrm{~mL}$ to $8 \mathrm{~mL}$ are injected underneath the incision by advancing the needle very slowly and never letting the needle get ahead of $3 \mathrm{~mm}$ to $4 \mathrm{~mm}$ of firm white tumesced subcutaneous tissue so the needle never contacts unanesthetized nerves. The goal is to get at least $4 \mathrm{~mm}$ to $5 \mathrm{~mm}$ of firm white tumesced subcutaneous tissue on either side of the incision. Reproduced with permission from reference 1

or given sedation if they had to undergo the procedure again. This is significant because, in many parts of the world outside of Canada, most patients still receive sedation or general anesthesia for CTR surgery. In Canada, more than $70 \%$ of CTR is performed with surgeonadministered pure local anesthesia without the need for sedation or a tourniquet (4). This is known as the 'wide-awake' approach, and it can be accomplished with injection of only lidocaine with epinephrine in the distal wrist and hand (5). The former drug provides adequate local anesthesia, while the latter achieves hemostasis.

Analysis of our study methodology showed weaknesses that we attempted to minimize. The first was that our patients had a selection bias in that they had to be willing to be injected by a learner. There was no way around this bias because the patients were required to give their consent to enter the study. Another was that there may have been a bias in the patient's responses because they may have felt obligated to please the surgeon or the learner. We attempted to reduce this bias by counselling the patients early in the study and explaining that we wanted an honest evaluation of the injection pain. In addition, patients were left alone to complete the evaluation, which remained 
confidential to participants, learners and surgeons. Another source of potential bias may have originated from our sample population consisting of more female subjects. We wanted to base the study on consecutive learners to avoid the bias of the potential difference in the abilities of the learners. Therefore, we could not control the ratio of males to females in our patient population.

One of the primary reasons patients may prefer sedation or general anesthesia to pure local anesthesia is the fear of the pain of the local anesthetic injection. This is because many patients have experienced unpleasantly painful local anesthetic injections. The present study provides evidence that minimally painful local anesthetic injection can be easily learned by student physicians and surgeons.

PRIZE WINNING PAPER: This presentation won for best Canadian resident poster award at the IPRAS meeting held in Vancouver, British Columbia, May 2011.

\section{REFERENCES}

1. Lalonde DH. "Hole-in-one" local anesthesia for wide-awake carpal tunnel surgery. Plast Reconstr Surg 2010;126:1642-4.

2. Mustoe TA, Buck DW II, Lalonde DH. The safe management of anesthesia, sedation, and pain in plastic surgery. Plast Reconstr Surg 2010;126:165e-176e.

3. Cepeda MS, Tzortzopoulou A, Thackrey M, et al. Adjusting the $\mathrm{pH}$ of lidocaine for reducing pain on injection. Cochrane Database Syst Rev 2010;(12):CD006581.

4. Leblanc MR, Lalonde J, Lalonde DH. A detailed cost and efficiency analysis of performing carpal tunnel surgery in the main operating room versus the ambulatory setting in Canada. Hand (N Y) 2007;2:173-8.

5. Lalonde D, Bell M, Benoit P, et al. A multicenter prospective study of 3,110 consecutive cases of elective epinephrine use in the fingers and hand: The Dalhousie Project clinical phase. J Hand Surg Am 2005;30:1061-7. 